Keywords: patient reported outcome; patient satisfaction; population study: prostate cancer; psychological well-being; quality of life; side effects

\title{
Patients' perceptions of the negative effects following different prostate cancer treatments and the impact on psychological well-being: a nationwide survey
}

\author{
Ulla-Sisko Lehto*,1, Heli Tenhola ${ }^{1,2}$, Kimmo Taari $^{3}$ and Arpo Aromaa ${ }^{1}$ \\ ${ }^{1}$ National Institute for Health and Welfare THL, Health Monitoring Unit, Helsinki Fl00271, Finland; ${ }^{2}$ University of Helsinki, Division \\ of Social Pharmacy; DRA Consulting Oy, Helsinki FI01510, Finland and 'University of Helsinki; Helsinki University Hospital, \\ Department of Urology, Helsinki Fl00029, Finland
}

Background: Although the prognosis of localised prostate cancer is good, the negative effects of prostate cancer treatment often impair patient quality of life. A growing number of men experience these negative effects over a longer time because of the increased incidence of and prolonged survival in prostate cancer, and the ageing of the population. Only a few studies have investigated the adverse effects of different prostate cancer treatments using large population-based samples.

Methods: We conducted a nationwide survey $(n=1239)$ to collect detailed information regarding the negative effects (i.e., the occurrence, perceived level and perceived bother since the beginning of the treatment) of prostate cancer treatments: radical prostatectomy, external beam radiotherapy, brachytherapy, hormone therapy and surveillance. Furthermore, we measured patient satisfaction with the outcome of the treatment and their psychological well-being (i.e., psychological symptoms and satisfaction with life) 5 years after diagnosis. The negative effects between the treatments were compared, and the determinants of satisfaction and psychological well-being were investigated.

Results: The negative effects of all types of active prostate cancer treatments were common and persistent (33-48\% reported symptoms at 5 years) and showed the known differences between the treatments. Prostatectomy and the radiotherapies caused urinary leakage; radiotherapy also caused symptoms of urinary irritation; and external radiation also caused bowel dysfunction. Most symptoms were considered highly bothersome. Most respondents (81-93\%) reported that their treatment negatively affected their sex lives; 70-92\% reported sexual dysfunction; and 20-58\% reported that their sex lives with their spouses had ended. Urinary symptoms were especially associated with poorer psychological outcomes. The perception of symptom level and bother had a greater effect on patient satisfaction and well-being than the symptoms per se.

Conclusion: Multiple and persistent negative effects follow active prostate cancer treatment, and these effects predict long-term patient satisfaction and psychological well-being. The harms and benefits associated with prostate cancer treatments should be considered when selecting whether and how to actively treat prostate cancer.

Prostate cancer is the most common cancer among men in developed countries, and 420000 new cases were diagnosed in Europe in 2012 (http://globocan.iarc.fr). In Finland, the mean annual number from 2009-2013 was 4791 cases (www.cancerregistry.fi). The incidence of prostate cancer is increasing worldwide. This increase is partially because of the widespread testing for

*Correspondence: Dr U-S Lehto; E-mail: ulla-sisko.lehto@thl.fi

Received 23 December 2015; revised 27 December 2016; accepted 19 January 2017; published online 21 February 2017

(C) 2017 Cancer Research UK. All rights reserved 0007-0920/17 
prostate-specific antigen (PSA; Penson et al, 2008b; van Leeuwen et al, 2013; Wever et al, 2013; Schröder et al, 2014). Most prostate cancers are detected when they are localised and the prognosis is good, and the prevalence is increasing also because of the ageing of the population. Although survival is good, quality of life (QoL) outcomes are impaired by the negative effects due to various prostate cancer treatments (Potosky et al, 2004; Miller et al, 2005; Frank et al, 2007; Penson et al, 2008a, b; Roth et al, 2008; Smith et al, 2009; Lehto et al, 2010, 2013; Pardo et al, 2010).

Harmful, multiple and persistent adverse effects are common after all forms of active prostate cancer therapy: radical prostatectomy, external beam radiation, brachytherapy and hormone therapy. The most common negative effects include urinary, sexual and bowel dysfunction, all of which can reduce patient well-being and QoL (Miller et al, 2005; Northhouse et al, 2007; Penson et al, 2008a, b; Roth et al, 2008; Smith et al, 2009; Pardo et al, 2010; Lehto et al, 2013; Gavin et al, 2015). The negative effects vary by treatment method. All active prostate cancer treatments result in sexual difficulties; prostatectomy and radiotherapies also in urinary dysfunction; external radiotherapy also in bowel dysfunction; and hormone therapy causes, for example, hot flushes and mood disturbances. Consensus does not exist regarding whether the benefits of active treatment for early prostate cancer, compared with those of surveillance, outweigh the negative effects of the treatment (Denberg et al, 2006; Penson et al, 2008b; van den Bergh et al, 2009; Carter et al, 2015; Klotz et al, 2015).

Various treatment options for prostate cancer follow specific guidelines such as the European Association of Urology Prostate Cancer Guidelines (https://uroweb.org/guideline/prostate-cancer) and the American Urological Association Guidelines (https:// www.auanet.org/education/clinical-practice-guidelines.cfm), which are based on the risk classification of the disease. However, the best treatment for long-term survival is still unknown (Wever et al, 2013). Specifically, no randomised controlled trial has compared prostatectomy with external beam radiotherapy. Patients usually participate in choosing their own treatments. This choice is important because different treatments can impair different areas of well-being and QoL. Differences in professional opinion concerning the best treatment option might complicate the situation for the patient at diagnosis (Denberg et al, 2006; Roth et al, 2008; Wever et al, 2013; Sooriakumaran et al, 2014). Both the prognosis and effect of the treatment on QoL should be considered when choosing a treatment for prostate cancer (Damber and Aus,
2008; Roth et al, 2008; Wever et al, 2013). Many men with localised prostate cancer do not benefit from definitive treatment (European Association of Urology Prostate Cancer Guidelines), and not all early local or locoregional prostate cancers require active treatment (Bul et al, 2013; Wever et al, 2013; Carter et al, 2015). In addition, the harms and benefits of population PSA screening are currently widely discussed (Auvinen et al, 2016). Screening with PSA detects some early prostate cancers that would never cause significant clinical problems during a man's lifetime. More information is needed to minimise the negative effects of prostate cancer and its treatments.

Using a population-based sample of men with prostate cancer diagnosis, we collected comprehensive information concerning the patient-reported negative effects (i.e., occurrence, perceived level and the perceived bother of the symptoms at any time, 'ever' and 'current') of different prostate cancer treatments 5 years after diagnosis. We also measured patient satisfaction with the outcome of the treatment and their psychological well-being (i.e., psychological symptoms and satisfaction with life) 5 years after diagnosis. The negative effects of the different treatments were compared, and the association among these negative effects, patient satisfaction and well-being was investigated.

\section{PATIENTS AND METHODS}

Sample and procedure. The Finnish Cancer Registry (www.cancerregistry.fi) collected a nationwide sample of every second incidence case diagnosed in Finland in 2004 on our behalf (Lehto et al, 2010; Lehto et al, 2015; Figure 1). We linked these data with the Finnish Population Register Centre and excluded patients who died before survey. After excluding patients without a recommendation from the treating hospital to participate in this study (11\%), and those whose address was not available, we mailed a questionnaire to 1723 men between January and May 2009. A telephone line was provided to the patients for questions. A further questionnaire was sent to non-respondents 1 month later.

We accepted 1239 returned questionnaires (72\%) for the study (Figure 1). These questionnaires represented $62.5 \%$ of the patients $(n=1984)$ who were alive at the time of the survey $(70 \%$ of those who were $<65$ years old, $67 \%$ of those who were $65-74$ years old, $60 \%$ of those who were $75-84$ years old, and $34.5 \%$ who were $\geqslant 85$ years old). The response rate and the age distribution of the

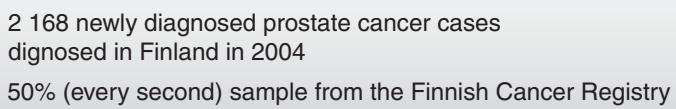

Figure 1 . The study sample. 
patients was similar across the five university hospital districts (geographic regions) in Finland (Lehto et al, 2010).

The questionnaire. The questionnaire was designed for the purposes of this study and constructed in collaboration with members of a prostate cancer patient organisation (Eturauhassyöpäpotilaiden tuki ry ERSY). These patients also participated in pilot studies to develop the questionnaire. The results of the first section of the questionnaire were previously reported (Lehto et al, 2015). The second section targeted the negative effects due to the treatment. We measured the occurrence, perceived level and the perceived bother of a given adverse effect at any time (ever) since the treatment with regard to each type of treatment the patient received, including radical prostatectomy, radiotherapies (i.e., external beam radiotherapy or brachytherapy), hormone therapy (other than neoadjuvant) and surveillance. (If any doubt or inconsistency appeared in the survey, then an expert medical researcher checked the treatment(s) implemented using the information the patient provided in the questionnaire or the information in the cancer registry data.). They were also asked whether the cancer had recurred.

The degree of the negative effects was evaluated with scales ranging from 0 (not at all) to 3 (a lot/strong/all the time) or with dichotomous no/yes answers. The patients were also asked whether they had had sex life with their spouse 6 months before the diagnosis (no/yes) and at any time after treatment (no/yes). Patient satisfaction was assessed using a scale ranging from 1 (completely adequate/satisfied) to 4 (completely inadequate/dissatisfied). Some open-ended questions including one regarding the negative effect(s) that the patient still suffered at the time of the survey were also asked.

Patient satisfaction with the overall outcome of the treatment and their psychological well-being were measured at the time of the survey. The patients indicated how satisfied they were with the outcome of their treatment using a scale ranging from 1 (completely satisfied) to 4 (completely dissatisfied). Psychological well-being was measured using two validated measures (Lehto et al, 2015): the psychological symptom items of the cancer-specific Rotterdam Symptom Checklist (deHaes et al, 1990), including irritability, depressed mood, nervousness, desperate feelings about the future, tension, anxiety, difficulty concentrating and worrying with scales ranging from 0 (not at all) to 3 (much), and the Satisfaction With Life Scale including statements: In most ways, my life is close to my ideal; The conditions of my life are excellent; I am satisfied with my life; So far I have the important things I want in life; If I could live my life over, I would change almost nothing (Diener et al, 1985).

We analysed the data using descriptive statistics and investigated the associations between the negative effects of the treatment and the outcome measures (i.e., satisfaction with outcome of the treatment, psychological symptoms and satisfaction with life) using a linear regression analysis $(B=$ regression coefficient). All statistical analyses were performed using SPSS version 22 and Stata version 11 .

Permissions and ethical aspects. The Ministry of Social Affairs and Health in Finland provided permission to obtain the Finnish Cancer Registry patient data. Experts in health psychology revised the questionnaire, and it was mailed to the patients from the National Public Health Institute (currently THL). The Ethics Committee of Helsinki University Hospital approved the research protocol.

\section{RESULTS}

The mean age of the respondents was 72 years old (range, 49-98 years), and thus the mean age at diagnosis has been 67 years old
(Table 1; Lehto et al, 2010, 2015). Approximately 80\% were married or cohabiting, and $88 \%$ were retired. Nearly half $(47 \%)$ reported receiving no or a very brief vocational education. Approximately $75 \%$ reported that they had another chronic condition (Table 1).

The most common treatments were radical prostatectomy (26\%) and external beam radiation (24\%) implemented as a single therapy (Table 1). Hormone (androgen deprivation) therapy was often used as an adjuvant treatment. However, $23 \%$ of the patients had undergone multiple treatments; thus, the total use of the different treatment modalities (alone or in combination) was higher. A total of $42 \%$ of the respondents received external beam radiotherapy, 33\% received hormonal therapy, 32\% received radical prostatectomy, 7\% received surveillance and $6.5 \%$ received brachytherapy (Lehto et al, 2015). Hormonal therapy was often (65\%) still going on at the time of the survey. Age was positively associated with hormonal therapy and surveillance but negatively associated with prostatectomy and brachytherapy. Having no other chronic condition was associated with prostatectomy. The Gleason score was positively associated with external radiotherapy and hormonal

\section{Table 1. Demographic characteristics of the survey sample ${ }^{a}$} and treatment for the prostate cancer $(N=1239)$

\begin{tabular}{|c|c|}
\hline & $\%(n)$ \\
\hline \multicolumn{2}{|l|}{ Age } \\
\hline$\leqslant 64$ & $20(248$ \\
\hline $65-74$ & $41(503)$ \\
\hline $75-84$ & $34(423$ \\
\hline 85 and over & $5(65)$ \\
\hline
\end{tabular}

\section{Marital status}

Married or cohabiting

Divorced

Widow

80 (988)

Never married

$7(82)$

$8(97)$

$4(45)$

\section{Vocational education ${ }^{b}$}

No vocational education

Vocational courses or school

Some college or college graduate

University degree

25 (305)

38 (465)

21 (256)

Other chronic condition (own report)

\begin{tabular}{|l|l}
\hline Any & 74 (900)
\end{tabular}

Coronary heart disease

Musculoskeletal disease

Diabetes

Other cancer

Other

$26(311)$

18 (213)

15 (181)

7 (86)

22 (267)

Gleason classification $(x+x)^{c}$

4 or less

5-6

7

8-10

10 (131)

40 (504)

26 (326)

13 (133)

Treatment for prostate cancer

Radical prostatectomy alone

External beam radiotherapy alone

Hormonal therapy alone $\mathbf{d}^{\mathbf{d}}$

External beam radiotherapy + hormonal therapy

Surveillance alone $\mathbf{e}^{\mathbf{2}}$

Brachytherapy alone

Prostatectomy + external beam radiotherapy

Other combination

\section{6 (319)}

24 (292)

16 (202)

13 (163)

6 (69)

$5(67)$

$4(50)$

$5(73)$

Note: some variables do not add up to $100 \%$ due to missing data.

${ }^{a_{F}}$ Finnish population is ethnically homogeneous in the age groups in question.

${ }^{\mathbf{b}}$ The education level varied between the geographical areas in favour to the capital Helsinki area.

${ }^{{ }^{c}}$ From the Cancer Registry data, available for $88.3 \%$ of the respondents.

$\mathbf{d}_{\text {Including orchiectomy. }}$

$\mathbf{e}_{\text {Either active surveillance or watchful waiting. }}$ 
therapy but negatively associated with brachytherapy and surveillance. Six per cent of the patients reported that their prostate cancer had recurred; however, a higher proportion reported additional treatments, which were obviously due to a relapse.

Negative effects of the treatments. The negative effects by treatment are shown in Table 2. Patients treated with prostatectomy and radiotherapies commonly reported urinary and sexual difficulties, and those with external radiotherapy reported also bowel dysfunction. Depending on the treatment, 33-48\% reported at least one current negative effect after 5 years, and this was more common after prostatectomy $(B=0.17, P<0.001)$ and external radiotherapy $(0.13, P<0.001)$ but less common after brachytherapy $(\mathrm{B}=-0.01, P<0.01)$.

Urinary dysfunction. More than $70 \%$ of the patients reported urinary leakage after prostatectomy, and $\sim 45 \%$ of those who were treated with external radiation or brachytherapy (Table 2). This symptom was more common after prostatectomy and external radiation $(P<0.001)$. This difference remained after adjusting for age. The perceived level of the leakage was also highest after prostatectomy (Figure 2A). Of those who received prostatectomy, $40 \%$ reported that the leakage had ceased within 3 months (Table 2), whereas $42 \%$ of patients receiving external radiation suffered from leakage for more than a year, and $50 \%$ of those patients reported that this symptom began as a late effect after the radiation therapy was over. Approximately $10 \%$ of the patients had urinary trouble (a qualitative report) at the time of the survey after prostatectomy, followed by $8 \%$ after external radiation, and $6 \%$ after brachytherapy. Approximately half of all patients reported that they had experienced unpleasant smell. This effect was more common after prostatectomy (age and Gleason score adjusted $\mathrm{B}=0.29, \quad P<0.001)$ and less common after brachytherapy $(\mathrm{B}=-0.09, P=0.086)$.

Additional urinary symptoms, including burning during urination, increased frequency or blood in the urine, and retention or straining, were reported after radiation therapy, that is, external radiation and brachytherapy (Table 2). Brachytherapy was more closely associated with burning $(B=0.36, P<0.001)$, increased frequency or blood in the urine $(B=0.23, P<0.1)$ and urinary retention $(B=0.31, P<0.01)$ than external radiation. Increased frequency/blood in the urine usually started during the radiotherapy, and it lasted longer than 1 year for 37\% (external radiation) and $25 \%$ (brachytherapy) of the patients. Urinary retention lasted longer than a year for 30 and $44 \%$ of patients.

The urinary symptoms bothered $74-80 \%$ of the patients who reported them, and $7-10 \%$ reported these symptoms as a major bother (Table 2). The degree of the overall bother was predicted by most of the symptoms in prostatectomy and external radiation (Table 3$)$. The most troublesome $(P<0.001)$ was the perceived level of the leakage; after prostatectomy also the level of the smell and after external beam radiotherapy also increased frequency/ blood in the urine and retention were closely associated $(P<0.001)$ with the perceived overall bother. Age decreased the perceived bother of the urinary symptoms after prostatectomy $(P<0.01)$.

Bowel dysfunction. Approximately half of the patients suffered from bowel dysfunction during or after external beam radiotherapy, whereas only $15 \%$ did so after brachytherapy (Table 2). The most common symptoms were diarrhoea and bleeding from the anus/bowel. Diarrhoea lasted less than 3 months in approximately half of the patients after external radiation; however, it lasted longer than a year in $32 \%$, and it started as a late effect in $25 \%$ of the patients. The bleeding was over in 3 months in $26 \%$ of the patients, whereas it lasted for more than a year in $59 \%$. Approximately $15 \%$ of the patients reported bowel dysfunction at 5 years after external beam radiotherapy, whereas only $4 \%$ reported this symptom after brachytherapy. Bowel dysfunction symptoms were considered harmful by $90 \%$ of the patients. Duration of diarrhoea was associated with the perceived bother of the bowel dysfunction $(B=0.24, P=0.021)$.

Negative effects on sex life. All active treatments considerably affected patients' sex lives; specifically, $81-93 \%$ of respondents reported an effect (Table 2 and Figure 2B). Prostatectomy was reported as having a stronger effect on patients' sex lives ('ever' during the 5 years after diagnosis) than the other treatments, even after adjusting for age and the Gleason score $(B=0.23, P<0.001)$. External beam radiotherapy $(\mathrm{B}=-0.16, P<0.001)$ and hormonal therapy $(\mathrm{B}=-0.29, P<0.001)$ had weaker effects. Of the patients who reported a permanent effect at five years, $67 \%$ indicated sexual difficulties after prostatectomy, and almost the same proportion after brachytherapy (Table 2). Permanent sexual difficulties were reported more often after prostatectomy (in 32\% of all the patients) than after external radiation (11\%) and brachytherapy (20\%).

Between 70 and $92 \%$ of the patients reported sexual dysfunction (impotence, loss of libido/sexual desire, or the loss of both potency and desire) depending on the treatment received (Table 2). More dysfunction was reported after prostatectomy $(B=0.18$, $P<0.001$, adjusted for age), hormonal therapy $(\mathrm{B}=0.11$, $P<0.001)$, and external radiotherapy $(B=0.07, P=0.006)$ than after the other treatments. Between 22 and $57 \%$ of the respondents reported impotence, most often after prostatectomy, whereas loss of sexual desire alone was rare (4-10\%; Figure 2C). 18-25\% reported the loss of both desire and potency after prostatectomy or radiotherapy, whereas $45 \%$ reported the loss of both after hormonal therapy.

Between 62 and $82 \%$ of the respondents reported having sex life with their spouse before treatment for prostate cancer (Table 2 and Figure 2D). Younger respondents $(B=-0.02$, $P<0.001)$ and those without a comorbid chronic condition $(\mathrm{B}=0.10, P=0.002)$ reported having sex more often. A prior sex life had been most common when the chosen treatment was prostatectomy $(\mathrm{B}=0.13, P<0.001$, when adjusted for age, the Gleason score and the presence of another chronic condition) but less common when it was surveillance $(B=-0.45, P<0.001)$. The patients' sex lives decreased considerably after all treatments, and it ended in $38 \%, 30 \%, 20 \%$ and $58 \%$ of the patients receiving prostatectomy, external radiation, brachytherapy and hormone therapy, respectively. A post-treatment sex life was more common after radiation therapy (52 and 69\% for external radiation and brachytherapy, respectively). $28 \%$ of the patients receiving hormone therapy reported having sex life with their spouse after treatment.

Across the different treatments, slightly different sexual effects predicted the overall effect of the treatment on sex life (Table 3 ). The most harmful effects across all treatments $(P<0.001)$ were the loss of both sexual desire and potency and the loss of sexual desire. The loss of potency showed a weaker association. A pre-treatment sex life with the spouse naturally predicted a stronger effect on sex life and the effect was weaker when post-treatment sex life was present. Age decreased the effect on sex life after prostatectomy $(P<0.1)$ and hormonal therapy $(P<0.01)$.

Side effects of hormonal therapy. The most common negative effect of hormonal therapy was hot flushes (73\%) followed by sore breasts (52\%), mood disturbances (46\%) and oedema of the feet (34\%; Figure 2E).

Patient satisfaction with the outcome of the treatment, psychological well-being, and the negative effects. Dissatisfaction with the treatment outcome at the time of the survey (i.e., proportion of patients reporting any amount of dissatisfaction) was highest after prostatectomy (42\%). 34\% of the patients were dissatisfied with the outcome of hormone therapy, $24 \%$ were 
dissatisfied with the outcome of external beam radiation, $22 \%$ were dissatisfied with the outcome of brachytherapy and 15\% were dissatisfied with the outcome of surveillance. The scale means were 1.55 (s.d. $=0.76), 1.48$ (s.d. $=0.79), 1.35$ (s.d. $=0.72), 1.34$ (s.d. $=0.77)$, respectively, for the active therapies (satisfaction with surveillance was measured as no/yes).

Three-quarters of the respondents reported at least one psychological symptom (the Rotterdam Symptom Checklist) at

Table 2. Negative effects in different treatments

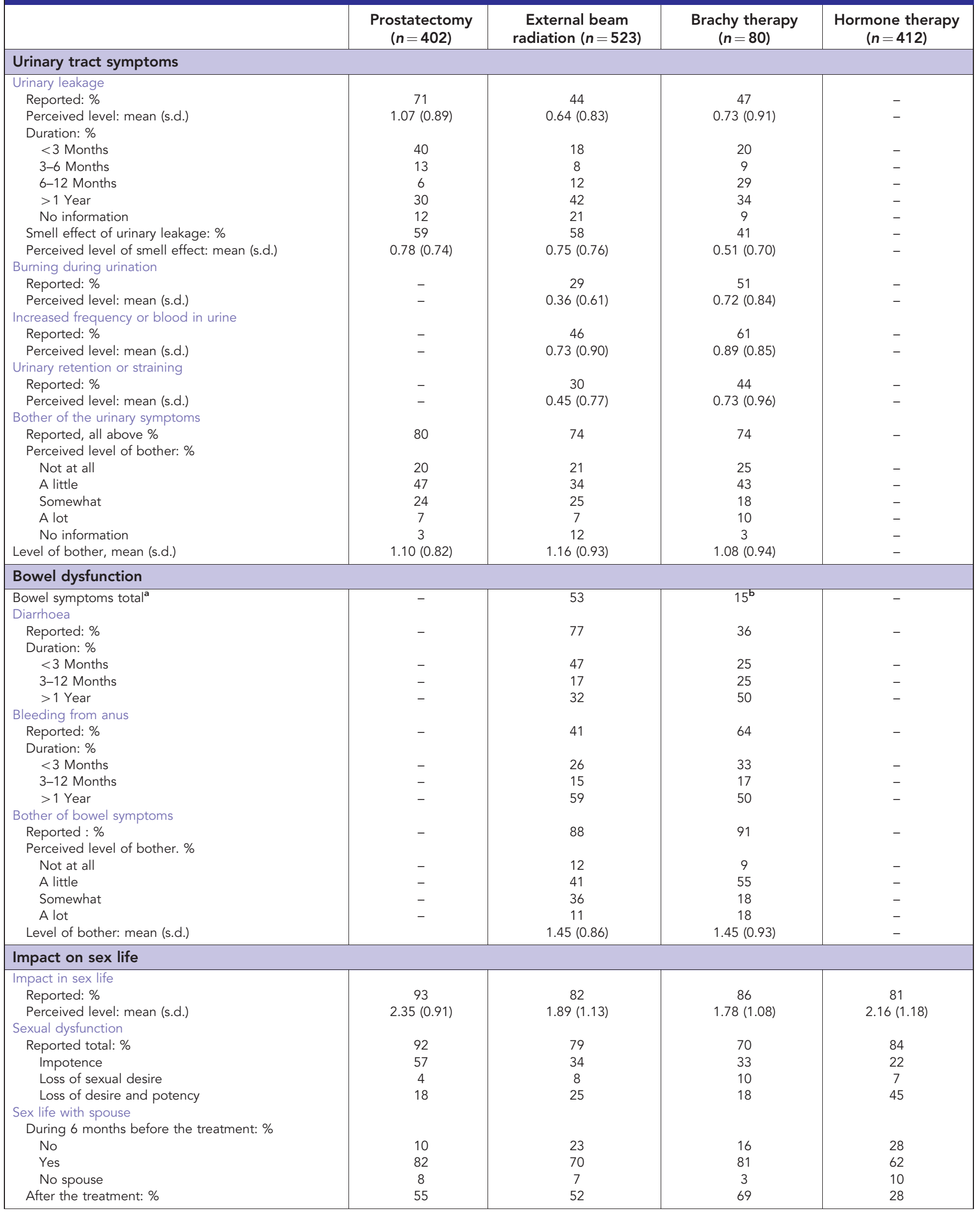




\section{Table 2. (Continued)}

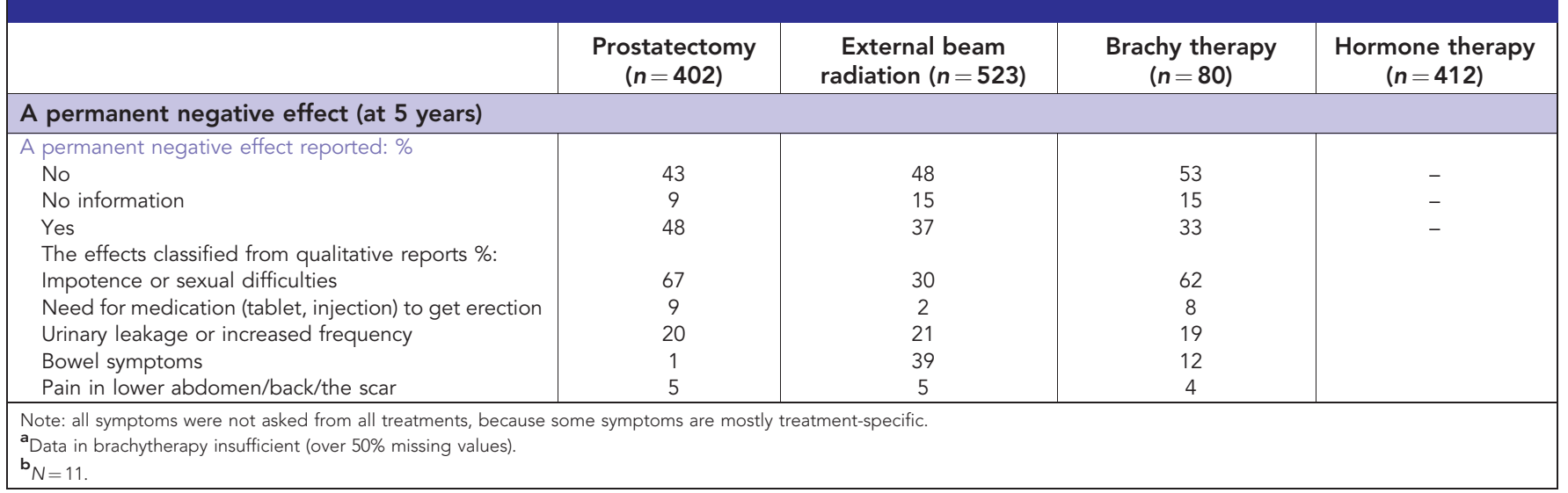

\section{A}

Urinary leakage after different treatments (age-adjusted), \%

- Not at all | A little | Sometime/somewhat | All the time

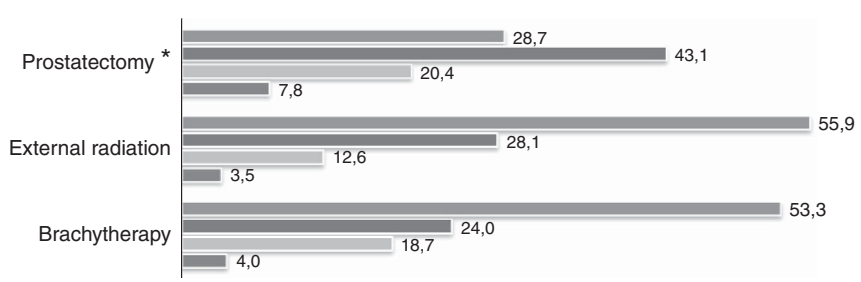

${ }^{*}$ Age associated with increased urinary leakage $(F=2.96, P=0.032)$.

B

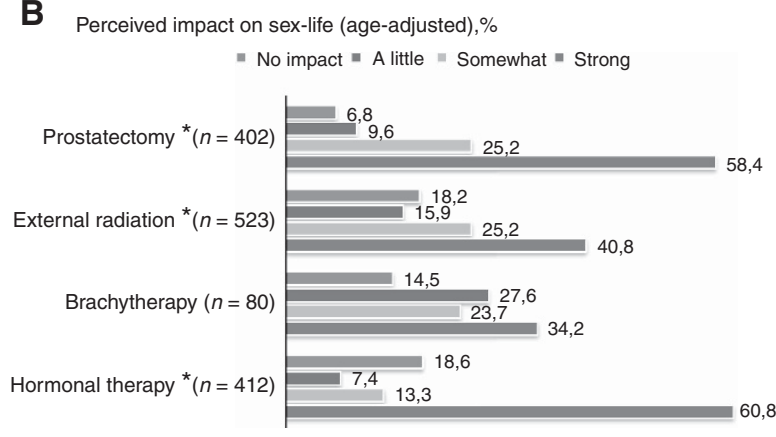

C

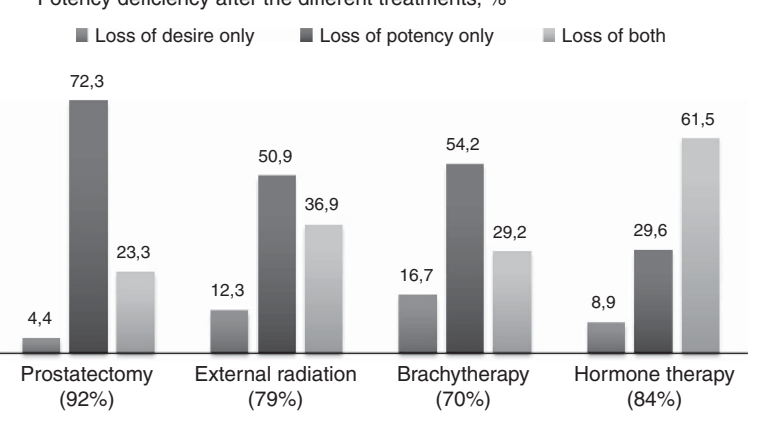

D

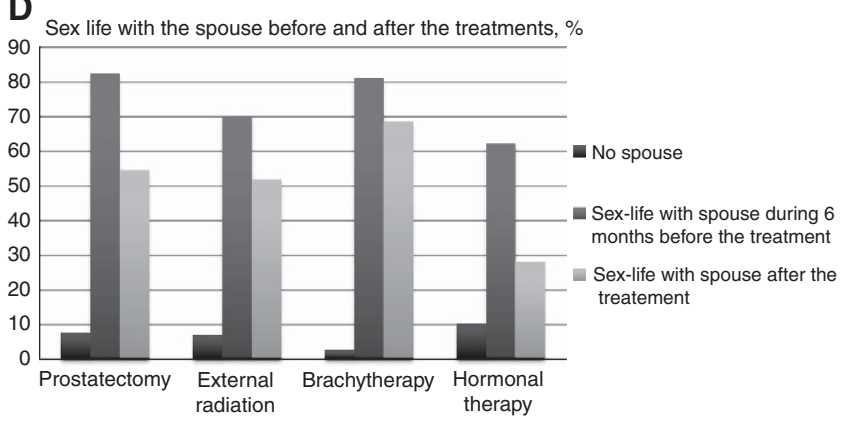

${ }^{*}$ Age decreased the impact.

\section{E}

Not at all A little Somewhat Much

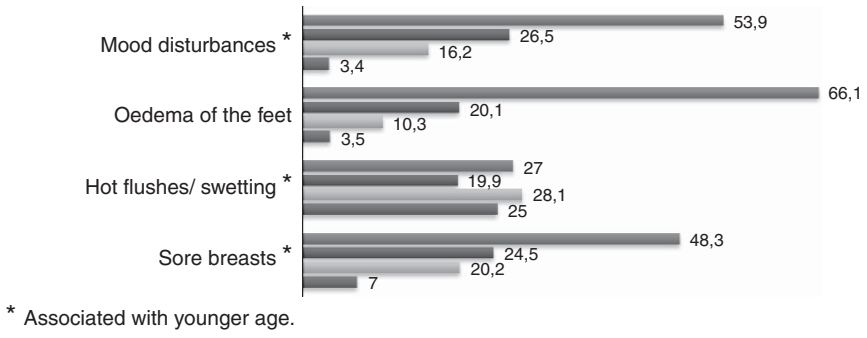

Figure 2. Negative effects in different treatments (Reproduced by kind permission Lehto et al, 2013). (A) Urinary leakage after different treatments (age-adjusted), \%. (B) Perceived impact on sex life (age-adjusted), \%. (C) Potency deficiency after different treatments, \%. (D) Sex life with the spouse before and after the treatment, \%. (E) Adverse effects of hormonal treatment, \%.

the time of the survey (total scale mea $n=4.39, \mathrm{SD}=4.6$; Lehto et al, 2015). The most common symptom was worrying (57\%), followed by irritability (46\%), nervousness (40\%) and problems concentrating (39\%). Regarding the satisfaction with life statements (the Satisfaction With Life Scale), the median response was 'mostly agree'. Brachytherapy was associated with a lower total level of psychological symptoms, whereas surveillance was associated with greater satisfaction with life (Lehto et al, 2015). Age was negatively associated with the total level of the psychological symptoms $(B=-0.05, P<0.05$ when adjusted 
Table 3. Associations between the urinary and sexual adverse effects and overall perceived bother of them

\begin{tabular}{|c|c|c|c|c|}
\hline & Prostatectomy & External radiation & Brachytherapy & Hormonal therapy \\
\hline & B & B & B & B \\
\hline \multicolumn{5}{|l|}{ Level of total bother of the urinary symptoms } \\
\hline $\begin{array}{l}\text { Predictors } \\
\text { Age } \\
\text { Gleason } \\
\text { Level of urinary leakage } \\
\text { Duration of urinary leakage } \\
\text { Smell effect of urinary leakage } \\
\text { Burning during urinating } \\
\text { Frequency or blood in urine } \\
\text { Retention or straining }\end{array}$ & $\begin{array}{l}-0.02^{\star \star} \\
0.04 \\
0.39^{\star \star \star} \\
0.10^{\star \star} \\
0.44^{\star \star \star}\end{array}$ & $\begin{array}{l}0.01 \\
-0.09 \dagger \\
0.40^{\star \star \star} \\
0.18^{\star \star} \\
0.17 \\
0.01 \\
0.24^{\star \star \star} \\
0.24^{\star \star}\end{array}$ & $\begin{array}{r}0.02 \\
0.12 \\
0.13 \\
0.13 \\
-0.10 \\
0.33 \\
-0.04 \\
0.38+\end{array}$ & \\
\hline Coefficient of determination $\mathrm{R}^{2}$ for the model & 0.49 & 0.46 & 0.40 & \\
\hline \multicolumn{5}{|l|}{ Level of impact of treatment on sex life } \\
\hline $\begin{array}{l}\text { Predictors } \\
\text { Age } \\
\text { Gleason } \\
\text { Impotence } \\
\text { Loss of sexual desire } \\
\text { Loss of both desire and potency } \\
\text { Sex life with spouse during } 6 \text { months before treatment } \\
\text { Sex life with spouse after treatment }\end{array}$ & $\begin{array}{l}-0.01 \dagger \\
0.04 \\
0.64^{\star \star} \\
1.11^{\star \star \star} \\
1.19^{\star \star \star} \\
0.18 \\
-0.20^{\star}\end{array}$ & $\begin{aligned} &- 0.01 \\
&- 0.06 \\
& 0.59^{\star \star \star} \\
& 1.19^{\star \star \star} \\
& 1.41^{\star \star \star} \\
& 0.65^{\star \star \star} \\
&-0.22^{\star}\end{aligned}$ & $\begin{array}{l}0.03 \\
0.05 \\
0.38 \\
1.16^{\star \star \star} \\
1.50 \star \star \star \\
0.38 \\
-0.05\end{array}$ & $\begin{array}{c}-0.02^{\star \star} \\
-0.03 \\
0.83^{\star \star} \\
1.44^{\star \star \star} \\
1.79^{\star \star \star} \\
0.38^{\star \star} \\
-0.36^{\star}\end{array}$ \\
\hline Coefficient of determination $\mathrm{R}^{2}$ for the model & 0.31 & 0.36 & 0.40 & 0.38 \\
\hline
\end{tabular}

for treatment modality and recurrence). Reported recurrence was associated with more psychological symptoms $(B=1.14$, $P<0.05)$.

Across the different treatments, different negative effects were associated with the outcomes (i.e., dissatisfaction with the treatment outcome and the well-being indicators (Table 4). The perceived level and the perceived bother of the symptoms (e.g., levels of bother of the urinary leakage and smell effect of the urinary leakage) were more strongly associated with the outcomes than the occurrence of the symptoms (measured as no/yes). Sexual dysfunction effects were more associated with the well-being outcomes among patients receiving prostatectomy than those receiving the other treatments. Sexual effects were of little consequence among the patients receiving radiation therapies, and their urinary symptoms explained most of the variation in the psychological well-being.

\section{DISCUSSION}

This nationwide survey collected detailed information regarding the negative effects of prostate cancer treatment by investigating patient perceptions of these effects and their bother at any time since the treatment during 5 years after diagnosis. We also measured patients' levels of satisfaction and psychological wellbeing five years after diagnosis. A 50\%-patient sample from a national cancer registry enabled us to study all men in Finland who were diagnosed with prostate cancer over 1 year. The response rate was high $(72 \%)$ for a postal survey addressing relatively elderly people. Of the patients in the cancer registry, $62.5 \%$ replied to our survey; only those over 84 years old were under-represented. The sample was representative of prostate cancer survivors 5 years after diagnosis. Along with the recent work from Ireland (Gavin et al, 2015), the current study is one of the first to describe the negative consequences of the various prostate cancer treatments in a population sample of patients of all ages.

As previously reported, the negative effects of all types of active prostate cancer treatments were common, often multiple, and persisted over the long term (Miller et al, 2005; Smith et al, 2009; Pardo et al, 2010; Resnick et al, 2013; Gavin et al, 2015). The known differences by treatment method were as follows: prostatectomy and the radiotherapies cause urinary symptoms; external beam radiotherapy also causes bowel dysfunction; and all active treatments were followed by sexual difficulties. Some of the treatments typically induce immediate transitory side effects (prostatectomy) and some treatment-specific late effects (radiotherapies), and all treatments result in long-term effects. We found that most of the adverse effects were considered highly bothersome. Approximately $75 \%$ of the patients stated that their urinary symptoms bothered them, and $90 \%$ stated that their bowel dysfunction was bothersome. All treatments had the potential to seriously harm the patients' sex lives.

Because we recorded all negative effects since the beginning of the treatment, our study found high levels of negative effects when compared with previous research (Lehto et al, 2013). We do not have information regarding when most of these negative effects occurred during the 5 years or whether they had passed; however, we have qualitative data concerning the negative effects present at the time of the survey. Several studies have measured side effects at a specific time point (Potosky et al, 2004; Miller et al, 2005; Penson et al, 2008a; Smith et al, 2009; Pardo et al, 2010; Gavin et al, 2015) and reported that there were more negative effects after prostatectomy than after other treatments at 3 years (Smith et al, 2009; Pardo et al, 2010) or at 5 years (Potosky et al, 2004; Penson et al, 2008a) post-diagnosis/treatment. This finding is in agreement with our results. However, one study (Miller et al, 2005) reported few differences between prostatectomy and external beam radiotherapy after six years. More recently, no significant differences in urinary, bowel or sexual function were found between prostatectomy and radiotherapy when evaluated at 15 years (Resnick et al, 2013).

The high level of urinary leakage experienced by patients receiving prostatectomy was often decreased quickly, and permanent urinary troubles were only slightly more common after prostatectomy than after external beam radiotherapy or brachytherapy. Age was negatively associated with the perceived 
Table 4. Negative effects of treatments associated with dissatisfaction with outcome of the treatment and psychological wellbeing

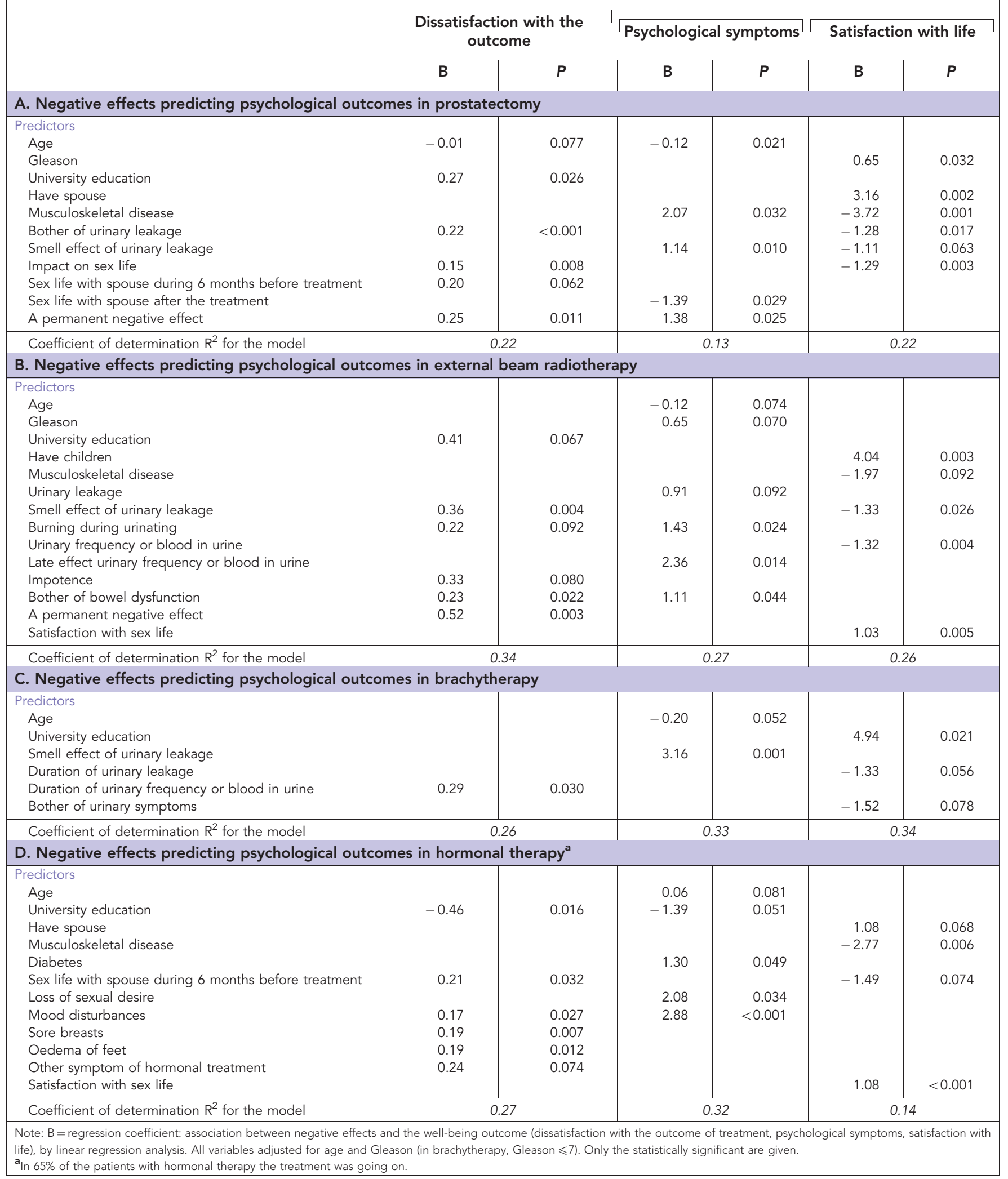

bother of the urinary symptoms, which suggests that these symptoms are better tolerated as patients grow older age. However, prostatectomy most strongly affected patients' sex lives. Operation typically resulted in sexual dysfunction, especially impotence (75\%), whereas impotence was less frequently associated with the other treatments (51-67\%). The patients reported far more often permanent sexual difficulties after prostatectomy (32\%) than after external radiation and brachytherapy ( $11 \%$ and $20 \%$, respectively). This number was even higher when troubles solved with medication were included. This finding corroborates those of 
previous studies (Potosky et al, 2004; Smith et al, 2009), indicating that prostatectomy often induces sexual dysfunction. The effect of prostatectomy on patients' sex lives was most likely stronger because these patients were younger, were more likely to have a sex life before treatment, and less likely to suffer from another chronic condition. Furthermore, prostatectomy typically led to impotence without the loss of sexual desire, which was strongly associated with perceived bother.

Among patients receiving external beam radiotherapy, urinary trouble and bowel dysfunction often started as a late effect after the treatment. Half of the patients reported bowel dysfunctions (diarrhoea or anal bleeding), and 25\% reported these effects as late, and often lasting for more than a year. In addition, 15\% reported bowel dysfunction after 5 years. The frequency of bowel dysfunction reported here matches previous reports, that is, 15$23 \%$ after 3 years (Smith et al, 2009; Pardo et al, 2010) and 13\% after 6 years (Miller et al, 2005). The absence of a sex life with one's spouse occurred less frequently after radiotherapy than after the other treatments. Approximately half of the patients who underwent external beam radiotherapy reported having a sex life with their spouse after the treatment; this decrease was small because only $70 \%$ reported a pre-treatment sex life.

Brachytherapy seemed less harmful than the other treatments; it rarely resulted in bowel dysfunction, and its effect on patients' sex lives was smaller than those of other treatments. However, urinary irritation symptoms (burning, frequency and retention) remained common. These patients differed from others with regard to many preceding factors: they were younger, their cancers had better prognoses (i.e., smaller Gleason score; high-risk prostate cancer is not treated with brachytherapy), and they commonly reported pretreatment sex lives. A comparison with the other treatments is complicated because brachytherapy was available only in certain hospital districts and it was widely used in one district. We previously found that psychological well-being after brachytherapy is better than that after other treatments (Lehto et al, 2015). Several studies have reported that brachytherapy causes fewer long-term side effects, especially sexual dysfunction and urinary incontinence (Frank et al, 2007; Aaltomaa et al, 2009; Pardo et al, 2010).

Surprisingly, patients receiving androgen deprivation therapy reported that their sex life was not more frequently affected than those receiving the other treatments; however, these patients were more likely to report a 'strong' effect. Age reduced the effect of hormonal therapy on sex life, and because only $62 \%$ of these patients reported having a sex life before treatment, they likely already had given up their sex life before their diagnosis, for example, due to ageing, illness or limitations in functional capacity. Thus, they had less sex lives to be affected. The decrease in having sex life with their spouse was nearly $60 \%$ of these patients; however, as many as $28 \%$ reported having a sex life with their spouse since the beginning of treatment.

We found that the negative effects of active prostate cancer treatment are associated with later satisfaction and psychological well-being. Urinary symptoms were more strongly associated with well-being outcomes than sexual difficulties. This result should not be generalised across all prostate cancer patients; individual differences in this matter are most likely strong. The association between sexual dysfunction and the treatment outcomes was somewhat stronger among patients receiving prostatectomy than those receiving other treatments. Some positive association was found between the Gleason score and better well-being. Could it be that patients with more severe diseases tolerate more negative effects of the treatment? On the whole, the perceived level and bother of the symptoms had a stronger effect on psychological outcomes than the occurrence of the symptoms per se.

We retrospectively measured the negative effects 5 years after the diagnosis of prostate cancer, and there may have been memory bias in the patients' recall of these effects. This might have biased some of our findings. More severe and longer lasting effects might be better recalled than short-term consequences. However, the disturbing adverse effects due to cancer treatment are likely to be remembered, even years later. We assessed the effects associated with each treatment; however, nearly $25 \%$ of the patients received multiple treatments. Thus, these patients might have difficulty separating the effects of individual treatments from each other. Furthermore, we did not always ask when the symptoms occurred or how long they lasted (and when we did, the patients' answers tended to be incomplete). The current symptoms were recorded only as the presence of a negative effect at the time of the survey via quantitative reports that we classified later. The negative effects and well-being outcomes were measured simultaneously; thus, their associations do not allow for direct conclusions regarding causality. In addition, it would have been preferable to have information about the same symptoms in the population. These data would have helped assess the effects of prostate cancer treatment compared with the symptoms of same-aged men.

Our results describe the negative effects of the treatments implemented in 2004 and 2005. The treatments have developed since then; however, we believe that prostate cancer patients and survivors still face many of these negative effects. We believe that our results also indicate the present situation, especially by illustrating the perceived harmfulness and bother of the symptoms. However, a new survey should be conducted to obtain up-to-date information concerning the negative effects of prostate cancer in the population and to assess the effects of the developing treatments.

The abundance of the symptoms and their bothersome nature draws attention to the harms and benefits of the active treatment of prostate cancer. An on-going debate exists regarding how and whether to actively treat patients with early-stage prostate cancer (Denberg et al, 2006; Bul et al, 2013; Wever et al, 2013; Carter et al, 2015; Klotz et al, 2015). A related discussion concerns the appropriateness of population PSA screening for prostate cancer (van Leeuwen et al, 2013; Schröder et al, 2014; Auvinen et al, 2016).

Prostate cancer and its associated treatments affect the lives of an increasing proportion of the elderly male population and their partners (Lehto et al, 2017). A growing number of men experience the negative effects of these treatments and for a longer time. Thus, the well-being of prostate cancer patients and prostate cancer survivors is also important from a public health perspective. The negative effects of the treatments described herein and their effects on well-being should be carefully considered when selecting a treatment for prostate cancer. In addition, methods should be developed to alleviate the negative effects associated with treatments and promote the QoL of men with prostate cancer diagnosis.

\section{ACKNOWLEDGEMENTS}

The Finnish Cancer Foundation financially supported reporting of this study. The Finland's Slots Machine Association RAY provided support for the preparation of the survey via the project 'Psychosocial Rehabilitation of Men with Prostate Cancer Diagnosis' by the prostate cancer patient organisation Eturauhassyöpäpotilaiden tuki ry ERSY. We also thank Sanni Helander MSc, who prepared the data for the statistical analyses, and Leena Kuivalainen $\mathrm{PhD}$, for her collaboration in developing the questionnaire.

\section{CONFLICT OF INTEREST}

The authors declare no conflict of interest. 


\section{REFERENCES}

Aaltomaa S, Kataja V, Lahtinen T, Palmgren J, Forsell T (2009) Eight years experience of local prostate cancer treatment with permanent I ${ }^{125}$ seed brachytherapy - morbidity and outcome results. Radiother Oncol 91: 213-216.

Auvinen A, Moss SM, Tammela TL, Taari K, Roobol MJ, Schröder FH, Bangma CH, Carlsson S, Aus G, Zappa M, Puliti D, Denis LJ, Nelen V, Kwiatkowski M, Randazzo M, Paez A, Lujan M, Hugosson J (2016) Absolute effect of prostate cancer screening: Balance of benefits and harms by center within the European Randomized Study of Prostate Cancer Screening. Clin Cancer Res 22: 243-249.

Bul M, Zhu X, Valdagni R, Pickles T, Kakehi Y, Rannikko A, Bjartell A, van der Schoot DK, Cornel EB, Conti GN, Boeve ER, Staerman F, Vis-Maters JJ, Vergunst H, Jaspars JJ, Strolin P, van Muilekom E, Schröder FH, Bangma CH, Roobol MJ (2013) Active surveillance for lowrisk prostate cancer worldwide: the PRIAS study. Eur Urol 63: 597-603.

Carter G, Clover K, Britton B, Mitchell A, White M, McLeod N, Denham J, Lambert S (2015) Wellbeing during active surveillance for localised prostate cancer: a systematic review of psychological morbidity and quality of life. Cancer Treat Rev 41: 46-60.

Damber J, Aus G (2008) Prostate cancer. Lancet 371: 1710-1721.

deHaes J, van Knippenberg F, Neijt J (1990) Measuring psychological and physical distress in cancer patients: structure and application of the Rotterdam Symptom Checklist. Br J Cancer 62: 1034-1038.

Denberg TD, Melhado TV, Steiner JF (2006) Patient treatment preferences in localized prostate carcinoma: The influence of emotion, misconception, and anecdote. Cancer 107: 620-630.

Diener E, Emmons R, Larsen R, Griffin S (1985) The satisfaction with life scale. J Pers Assess 49: 71-75.

Frank S, Pisters L, Davis J, Lee A, Basset R (2007) An assessment of quality of life following radical prostatectomy, high dose external beam radiation therapy and brachytherapy ionide implantation as monotherapies for localized prostate cancer. J Urol 177: 2151-2156.

Gavin AT, Drummond FJ, Donnelly C, O'Leary E, Sharp L, Kinnear HR (2015) Patient-reported 'ever had' and 'current' long-term physical symptoms after prostate cancer treatments. BJU Int 116: 397-406.

Klotz L, Vesprini D, Sethukavalan P, Jethava V, Zhang L, Jain S, Yamamoto T, Mamedov A, Loblaw A (2015) Long-term follow-up of a large active surveillance cohort of patients with prostate cancer. J Clin Oncol 33: $272-277$.

Lehto U-S, Aromaa A, Tammela T (2017) Experiences and psychological distress of spouses of prostate cancer patients at time of diagnosis and primary treatment. Eur J Cancer Care (under revision).

Lehto U-S, Helander S, Aromaa A (2010) Eturauhassyöpään sairastunut tarvitsee tietoa ja tukea. Valtakunnallinen tutkimus hoidosta ja potilaiden kokemuksista. Experiences of men diagnosed with prostate cancer in Finland in 2004; with English Abstract. Suom Laakaril 48: 3961-3968.

Lehto U-S, Helander S, Taari K, Aromaa A (2015) Patient experiences at diagnosis and psychological well-being in prostate cancer: a Finnish national survey. Eur J Oncol Nurs 19: 220-229.

Lehto U-S, Tenhola H, Taari K, Aromaa A (2013) Eturauhassyövän hoitojen haitat ja potilaiden tyytyväisyys. Suom Laakaril 46: 2997-3005.

Miller D, Sanda M, Dunn R, Montie J, Pimentel H, Sandler H, McLaughlin W, Wei J (2005) Long-term outcomes among localized prostate cancer survivors: Health-related quality-of-life changes after radical prostatectomy, external radiation, and brachytherapy. J Clin Oncol 23: 2772-2780.

Northhouse L, Mood D, Montie J, Sandler H, Forman J, Hussain M, Pienta K, Smith D, Sanda M, Kershaw T (2007) Living with prostate cancer: Patients' and spouses' psychosocial status and quality of life. J Clin Oncol 25: 4171-4177.
Pardo Y, Guedea F, Aguiló F, Fernández P, Macias V, Mariño A, Hervás A, Herruzo I, Ortiz MJ, Ponce de León J, Craven-Bratle J, Suárez JF, Boladeras A, Pont A, Ayala A, Sancho G, Martinez E, Alonso J, Ferrer M (2010) Quality-of-life impact of primary treatments for localized prostate cancer in patients without hormonal treatment. J Clin Oncol 28: 4687-4696.

Penson D, McLerran D, Feng Z, Li L, Albertsen P, Gilliland F, Hamilton A, Hoffman R, Stephenson R, Potosky A, Stanford J (2008a) 5-year urinary and sexual outcomes after radical prostatectomy: results from the Prostate Cancer Outcomes study. J Urol 179: S40-S44.

Penson D, Rossignol M, Sartor A, Scardino P, Abelhaim L (2008b) Prostate cancer: epidemiology and health related quality of life. Urology 72(Supplement 6A): 3-11.

Potosky AL, Davis WW, Hoffman RM, Stanford JL, Stephenson RA, Penson DF, Harlan LC (2004) Five-year outcomes after prostatectomy or radiotherapy for prostate cancer: The Prostate Cancer Outcomes Study. J Natl Cancer Inst 96: 1358-1367.

Resnick MJ, Koyama T, Fan K-H, Albertsen PC, Goodman M, Hamilton AS, Hoffman RM, Potosky AL, Stanford JL, Stroup AM, Van Horn RL, Penson DF (2013) Long-term functional outcomes after treatment for localized prostate cancer. $N$ Engl J Med 368: 436-445.

Roth A, Weinberger M, Nelson C (2008) Prostate cancer: quality of life, psychosocial implications and treatment choices. Future Oncol 4: 561-568.

Schröder FH, Hugosson J, Roobol MJ, Tammela TL, Zappa M, Nelen V, Kwiatkowski M, Lujan M, Maattanen L, Lilja H, Denis LJ, Recker F, Paez A, Bangma CH, Carlsson S, Puliti D, Villers A, Rebillard X, Hakama M, Stenman UH, Kujala P, Taari K, Aus G, Huber A, van der Kwast TH, van Schaik RH, de Koning HJ, Moss SM, Auvinen A (2014) Screening and prostate cancer mortality: results of the European Randomised Study of Screening for Prostate Cancer (ERSPC) at 13 years of follow-up. Lancet 384: 2027-2035.

Smith DP, King MT, Egger S, Berry MP, Stricker PD, Cozzi P, Ward J, O'Connell DL, Armstrong BK (2009) Quality of life three years after diagnosis of localised prostate cancer: population based cohort study. BMJ 339: b4817.

Sooriakumaran P, Nyberg T, Akre O, Haendler L, Heus I, Olsson M, Carlsson S, Roobol MJ, Steineck G, Wiklund P (2014) Comparative effectiveness of radical prostatectomy and radiotherapy in prostate cancer: observational study of mortality outcomes. BMJ 348: g1502.

van den Bergh RC, Essink-Bot M-L, Roobol MJ, Wolters T, Schröder FH, Bangma CH, Steyerberg EW (2009) Anxiety and distress during active surveillance for early prostate cancer. Cancer 115: 3868-3878.

van Leeuwen PJ, Kranse R, Hakulinen T, Hugosson J, Tammela TL, Ciattoy S, Roobol MJ, Zappa M, de Koning HJ, Bangma CH, Moss SM, Auvinen A, Schröder FH (2013) Impacts of a population-based prostate cancer screening programme on excess total mortality rates in men with prostate cancer: a randomized controlled trial. J Med Screen 20: 33-38.

Wever EM, Heijnsdijk EA, Draisma G, Bangma CH, Roobol MJ, Schröder FH, de Koning HJ (2013) Treatment of local-regional prostate cancer detected by PSA screening: benefits and harms according to prognostic factors. Br J Cancer 108: 1971-1977.

This work is published under the standard license to publish agreement. After 12 months the work will become freely available and the license terms will switch to a Creative Commons AttributionNonCommercial-Share Alike 4.0 Unported License. 